\title{
Considerações acerca de uma determinada prática teatral: Artaud, sua cru- eldade e seu tempo.
}

Marinê de Souza Pereira (Bolsista PET/CAPES DF/USP/SP)

Tutor: Caetano Ernesto Plastino

Orientadora: Marilena de Souza Chaui

"Lá onde outros propõem suas obras, eu não pretendo fazer outra coisa senão mostrar meu espírito."1

Explosivo, dono de uma lucidez invejável, louco rejeitado pela sociedade e mantido preso por vários anos em uma casa de recuperação, tal era o quadro de controvérsias que o cercava em sua própria época. Objeto de muitos escritos posteriores que tentam capturar a essência de seu pensamento, Antonin Artaud aparece hoje como um mito a ser desvendado, esclarecido e conhecido. Certamente, tendo em vista a sua importância e a influência exercida sobre todas as concepções de teatro que se the seguiram, faz-se mesmo necessário estudá-lo, entender a sua forma de pensar o teatro - que é já um fazer, uma atitude diante do mundo, uma posição crítica sobre a sua época.

Esse texto nada mais é do que uma nova tentativa de compreendê-lo até onde isso é possivel e não tem nenhuma outra pretensão. Para tanto, uma peça será analisada: "II n'y a plus de firmament" Apesar de se tratar de uma obra inacabada, consideramos que por seu intermédio poderemos discutir alguns aspectos importantes da concepção de teatro artaudiana. Sendo este o nosso objetivo, não apresentaremos sistematicamente toda a peça, mas apenas os pontos relevantes para o nosso intento, os quais não poderemos de forma alguma esgotar aqui nesta discussão.

Pela leitura das primeiras linhas da peça somos já transportados para o universo teatral de Artaud, para o ponto central de uma encenação do teatro da crueldade:

Obscurité. Dans cette obscurité explosions. Harmonies coupées net. Sons bruts. Détimbrages de sons.

Efeitos provocadores de uma sensação não esperada. Efeitos que agem diretamente sobre o espectador, despertando os seus sentidos. Efeitos, enfim, capazes de explorar um sentimento primário que traduz, de certa forma, quase todos os outros: o medo. A encenação, para Artaud, deve ser capaz de fazer a platéia gritar. Deve ir o mais longe possível na exploração da nossa sensibilidade nervosa e, para isso, é preciso que ela faça uso de todas as técnicas passíveis de serem percorridas: ritmos, sons, palavras, ressonâncias e trinados. O medo não é considerado um sentimento paralisante e inibidor do homem, mas o ponto inicial de um processo capaz de atingir, para além da sensibilidade, a razão e a imaginação.

Artaud propõe uma nova linguagem teatral em detrimento da linguagem do texto utilizada pelo teatro ocidental o qual só considerava como linguagem a palavra articulada e escrita. Essa obsessão pela palavra clara e que diga tudo leva, segundo Artaud, ao ressecamento das palavras e é por sua causa que o "teatro perdeu sua verdadeira razão de ser e que estamos desejando um silêncio em que possamos ouvir melhor a vida."3 Não 
se trata de ignorar o texto ou suprimi-lo da cena, mas de conceder aos outros elementos cênicos um valor igual. Trata-se de acabar com o predomínio do teatro psicologista incapaz de falar às massas, as quais têm buscado no circo ou no cinema as satisfações violentas que não as decepcionam. Trata-se, sobretudo, de colocar em cena uma linguagem capaz de falar ao organismo todo, que atinja os sentidos e por meio deles o entendimento, uma vez que "não se separa o corpo do espírito, nem os sentidos da inteligência, da mesma forma a separação entre teatro de análise e mundo plástico é estúpida." ${ }^{4}$ Segundo Artaud, as massas pensam primeiro com os sentidos e o Teatro da Crueldade propõe-se a recorrer ao espetáculo de massas.

Para que o teatro volte a despertar a atenção geral, ele precisa assumir a sua única expressão de fato real: a expressão no espaço. Isso significa que ao invés de voltar a textos definitivos, é preciso romper com a sua sujeição ao texto e reencontrar uma espécie de linguagem única, "a meio caminho entre o gesto e o pensamento."5 A definição dessa linguagem, por sua vez, só pode se dar pelas possibilidades da expressão dinâmica e no espaço em oposição às possibilidades de expressão da palavra dialogada. Ora, o "teatro da crueldade quer fazer florescer o espaço e fazê-lo falar, dando uma voz às massas e às superfícies, desprezando as individualidades psicologizantes."

É preciso que o teatro volte a ocupar o seu lugar e a sua importância e possa abalar as nossas representações para que passemos por aquilo que Artaud chamou de "terapia da alma" Assim, o Teatro da Crueldade pretende ser terapêutico e isso só é possível por um tratamento cruel, capaz de destruir a existência para reconstruir um novo homem. Freqüentemente a palavra crueldade é relacionada com terror ou sangue, o que simplifica a questão. Tais recursos podem ser utilizados pela crueldade artaudiana, mas o sentido desta é muito mais amplo, não se tratando apenas de uma crueldade física ou moral, e sim "de uma crueldade ontológica, ligada ao sofrimento de existir e à miséria do corpo humano."7 Artaud reivindica o direito de romper com o uso comum das palavras e, dessa maneira, pretende voltar às suas origens etimológicas a fim de evocar-lhes uma noção concreta.

Voltando para a ação que se passa nessa peça, vemos que do início até o final do "Movimento I" algumas palavras são ouvidas, mas não se pode entender o que elas dizem, tamanho é o barulho e a alternância de sons e gritos que as cortam. Nesse trecho podemos perceber bem como isto se dá:

Tous ces textes coupés de passages de cris, de bruits, de tornades sonores que couvrent tout. Et une voix obsédante et énorme annonce une chose qu'on ne comprend pas.

Certamente, a importância das palavras aqui está na sua não concretização, na maneira como são deixadas inacabadas, ou como são bruscamente interrompidas pelos outros elementos. Por serem as palavras a forma mais comum de comunicação, a sua incompletude, nesse caso, leva a um sentimento de estranheza, devido à sua impossibilidade de compreensão.

É que as palavras assumem na peça um sentido que vai além do que lhes é convencional, elas falam não mais ao entendimento, mas aos sentidos, tornam-se um movimento, criam um ritmo e uma entonação novos. O teatro deve, segundo Artaud, "extrair da palavra sua possibilidade de expansão fora das palavras." Efetivando isso, tudo adquirirá um novo sentido, a linguagem se tornará viva, "a luz assumirá a aparência de verdadeira linguagem e as coisas da cena, palpitantes de significação, se ordenarão, mostra- 
rão figuras."

A grande voz anunciada na cena e que não é entendida, apesar de ser ouvida, aparece como se se tratasse de um sonho:

On entend cela comme une grande voix large, étendue, mais dans un rêve, et cela recommence indéfiniment jusqu'à la fin de la scène.

No Teatro da Crueldade, as palavras possuem o mesmo peso dos outros elementos e têm um valor semelhante ao que lhes cabe nos sonhos. Esta é a sensação pretendida por Artaud: a de um sonho. Ele quer fazer do teatro uma realidade na qual se possa acreditar. Como os nossos sonhos agem sobre nós e a realidade age sobre eles, acreditaremos nos sonhos do teatro se forem apresentados de fato como sonhos e não como decalque da realidade. Consequentemente, cada espectador poderá "liberar a liberdade mágica do sonho", o que só é possível se ela for marcada pelo terror e pela crueldade, ou pelas palavras do próprio Artaud: "Daí o apelo à crueldade e ao terror, mas num plano vasto, e cuja amplidão sonda nossa vitalidade integral, nos coloca diante de todas as nossas possibilidades."10

Em meio a todo o turbilhão de acontecimentos que se passam na peça, sem que se possa compreender ao certo o que está ocorrendo, há uma parada repentina:

Arrêt brusque. Tout recommence. Tout le monde reprend sa place comme se de rien n'était.

Logo em seguida,

Le carrefour recommence à grouiller.

Tudo cessa e retorna inesperadamente ao início, ao alarido do começo. Veremos que tal coisa se passará em todas as mudanças de um movimento para outro. Uma justificativa possível para essa alternância de estados pode ser, portanto, a mudança dos atos. Outra possibilidade está, contudo, na maneira como Artaud concebe a cena: não linear, fazendo sempre uso de círculos e reviravoltas. Exemplos disso são os esquemas de movimentação para serem cumpridos pelas personagens em cena pode-se observar como em grande parte esta movimentação é circular. Na tragédia "Os Cenci", o recurso ao giro, ao eterno retorno que marca a vida no universo, traduz-se pela presença de uma roda em cena à qual é presa a personagem feminina principal da peça, para a sua punição. Da mesma forma, o giro é utilizado no espaço, concebido de maneira a colocar o público no centro, em torno do qual deve desenvolver-se a cena. No texto "O teatro e a crueldade", inserido em O Teatro e seu Duplo, Artaud explicita melhor sua idéia: "É para apanhar a sensibilidade do espectador por todos os lados que preconizamos um espetáculo giratório que, em vez de fazer da cena e da sala dois mundos fechados, sem comunicação possível, difunda seus lampejos visuais e sonoros sobre toda a massa dos espectadores"11

O "Movimento II" inicia-se com hipóteses sobre o que pode estar ocasionando todo - conflito em cena: a guerra ou a peste. A introdução dessa primeira tentativa de explicação é feita por uma mulher questionando um agente a respeito do que se passa:

Monsieur l'agent, si c'est la guerre ou la peste, est-ce qu'on réquisitionnera mon chien?

Estes são dois conceitos extremamente importantes no pensamento de Artaud. Não podemos esquecer que essa peça foi escrita em um período anterior à segunda grande guerra e que quem viveu esse momento não pôde se abster de pensá-lo. Como bem observou Vera Lúcia Felício no volume A Procura da Lucidez em Artaud: tal qual uma 
epidemia, a desordem, as revoluções e os cataclismas naturais da guerra descarregamse na sensibilidade de quem os observa. ${ }^{12}$

A peste, por sua vez, está intimamente ligada ao Teatro da Crueldade. A relação entre ambos se dá porque "o estado do pestífero que morre sem destruição da matéria, tendo em si todos os estigmas de um mal absoluto e quase abstrato, é idêntico ao estado do ator integralmente penetrado e transtornado por seus sentimentos, sem nenhum proveito para a realidade" deve-se levar em conta que o público tanto do pestilento quanto do teatro é formado de inertes e delirantes.

$O$ teatro e a peste constituem-se verdadeiras epidemias ${ }^{13}$ Os dois se assemelham não apenas por serem contagiosos, mas por serem a revelação, a afirmação, a exteriorização de um fundo de crueldade latente e "através do qual se localizam num indivíduo ou num povo todas as possibilidades perversas do espírito." ${ }^{14} \mathrm{Em}$ um momento de peste ou de guerra, as preocupações se alteram e as pessoas se mostram tal qual elas são, e, assim como no teatro, realiza-se um vazamento de abcessos tanto morais quanto sociais, coletivamente. Dessa forma, do ponto de vista humano, a ação do teatro como a da peste é benfazeja, na medida em que mostra os homens como eles realmente são, fazendo cair a máscara e convidando a assumir diante do destino uma atitude heróica ${ }^{15}$

A desordem em cena e a incompreensão do que se passa convidam as personagens a uma atitude heróica. Nesse momento, no entanto, introduz-se uma explicação, através de um alto-falante, sobre o que está acontecendo:

IMMENSE DÉCOUVERTE. LE CIEL MATÉRIELLEMENT ABOLI. LA TERRE A UNE SECONDE DE SIRIUS. IL N'Y A PLUS DE FIRMAMENT. LA TÉLÉGRAPHIE CÉLESTE EST FAITE. LE LANGAGE INTERPLANÉTAIRE EST ÉTABLI.

Esta explicação seguramente não esclarece nada e, contudo, é capaz de fazer com que tudo volte ao "normal", ouvem-se gritos de alegria, risos, a loucura some deixando os homens voltarem aos seus divertimentos diários. Todas as questões e angústias suscitadas pelo medo do desconhecido desaparecem. Os homens aceitam a determinação que lhes é imposta e se acalmam, já não precisam tomar o comando do seu destino, entregam-no a algo que lhes é desconhecido e que assumirá as responsabilidades dos seus atos. Não conseguem fazer o enfrentamento necessário à liberdade, fogem.

Uma única voz parece lembrar a todos que nada foi realmente esclarecido:

- Je ne comprends tout de même pas, et puis qu'est-ce que ça peut nous foutre? Estce une raison pour tout déglinguer?

Seguramente ninguém lhe dá ouvidos e tudo permanece no ritmo corriqueiro das ações impensadas e frouxamente realizadas.

Eis o reflexo do estado de paralisação em que a sociedade se encontra. Segundo Artaud, nessa época nada adere mais à vida, as coisas começam a perder a sua razão de existir. Todos exigem uma magia mas têm medo de uma vida totalmente entregue a ela. Nas suas palavras: "se falta enxofre à nossa vida, ou seja, se lhe falta uma magia constante, é porque nos apraz contemplar nossos atos e nos perder em considerações sobre as formas sonhadas de nossos atos, em vez de sermos impulsionados por eles." ${ }^{16}$

Nesse momento da peça, descobrimos sobre o que centralmente ela versa: uma tragédia cósmica. Esse libreto de ópera inacabado é, nas palavras de Virmaux, "a prova decisiva de que essa obsessão por uma catástrofe cósmica não era fingida por interesse publicitário"17 Ele é uma das obras mais notáveis de seu autor "pois exprime e coloca com grande força sua obsessão pelo fim do mundo"18 Tal obsessão correspondia a uma 
convicção íntima sua, vendo tudo se esboroar em si e ao seu redor, e ela foi compartilhada por numerosos artistas nesse período entre as duas guerras ${ }^{19}$

Voltando à cena, de acordo com a circularidade já mencionada, tudo se altera novamente dando início ao "Movimento IIl". A calma e pacata aceitação de algo alheio ao entendimento da situação é repentinamente transformada em novos conflitos. Podemos imaginar que isso ocorre para nos mostrar que não estamos no âmbito da vida comum, mas "do seu duplo", onde todas as coisas imaginadas podem de fato se realizar, revelando a possibilidade da não submissão frente ao cotidiano insípido da época. Essa mudança é feita por meio de um canto revolucionário que vai se tornando mais alto, faz as personagens voltarem e se misturarem em grupos responsáveis por disputas isoladas:

On échange des horions. On bouscule des femmes. Des gifles claquent.

O vaivém dos estados de ação nega justamente a possibilidade de estagnação e é, de alguma maneira, um convite a atitudes novas e inesperadas, capazes de agitar a vida e de impor-lhe uma nova conduta.

A partir desse instante, o ritmo da peça se altera. São introduzidos dois instrumentos de percussão tam-tams - um grave e outro muito agudo, os quais realizarão o som que se seguirá. Mais tarde um tambor também será utilizado. Os instrumentos musicais têm, para Artaud, "a necessidade de agir diretamente e profundamente sobre a sensibilidade pelos órgãos." ${ }^{20}$ Neles, além do som que lhes é comum, pode-se buscar qualidades estranhas, bem como barulhos novos e até mesmo insuportáveis. Eles devem ser utilizados na sua condição de objetos, como se fizessem parte do cenário.

Surge em cena, ao mesmo tempo que os tam-tams, um coro, cuja voz acompanhará o seu ritmo. Certamente há aqui uma retomada do teatro grego. Sabemos que o coro era parte essencial nas tragédias antigas, sendo mesmo tratado como uma personagem. Comentando sempre o que acontecia ou iria acontecer, ele era responsável por nada se suceder sem passar pela discussão ou denúncia. Ora, Artaud retorna a essa espécie de espetáculo teatral porque a considera extremamente importante: ela se relaciona com uma época em que o teatro cumpria uma função. Os Mitos colocados em cena exerciam influência sobre a vida das pessoas, pois representavam os seus valores, as suas angústias e medos. Quanto aos Mitos da vida moderna, foi o cinema que os assumiu e, segundo Artaud, além de não levarem a nada, dão as costas ao espírito. Foi dessa nossa atualidade patética e mítica que o teatro se desviou: "e é com justa razão que o público se afasta de um teatro que ignora a tal ponto a atualidade"21

Podemos, portanto, repreender o teatro, tal como é praticado, por uma terrível falta de imaginação. Criar Mitos é o verdadeiro objetivo do teatro, "traduzir a vida sob seu aspecto universal, imenso, e extrair dessa vida imagens em que gostaríamos de nos reencontrar."22 Não é a pretensão de Artaud, no entanto, voltar às imagens expiradas dos velhos Mitos, e sim às forças que neles se agitam. Trata-se de retornar, através dos meios modernos e atuais, "à idéia superior da poesia e da poesia pelo teatro que está por trás dos Mitos contados pelos grandes trágicos da antigüidade"23 Ou nos mostramos capazes de tal realização, ou "só nos resta nos abandonarmos sem reação e imediatamente, e reconhecer que só servimos mesmo para a desordem, a fome, o sangue, a guerra e as epidemias." ${ }^{4}$ Em outro texto presente nas suas "Mensagens Revolucionárias" Artaud aborda novamente essa questão mostrando como o mito encontrado no teatro é relevante nessa época em que se faz presente um estado generalizado de caos espiritual: "Se nós procuramos criar um mito no teatro, é para encarregá-lo de todos os horrores de um 
século que nos faz crer em nosso fracasso na vida" 25

A presença do coro dá outro fôlego à encenação, na qual havia o predomínio da linguagem imagética e as palavras em cena ou eram entrecortadas, ou ditas em diálogos minúsculos dos quais não se podia entender muita coisa. Com o coro começa a haver um diálogo capaz de dizer tudo o que está ocorrendo, não os motivos pelos quais a confusão está instaurada, mas as características desta, que nada mais são do que um reflexo das características da época:

Le vol, le viol, la maladie,

le sang, l'ordure, l'incendie!(...)

Le vide, le vide, le vide...

A poesia que não temos mais em nós e não conseguimos também encontrar nas coisas reaparece pelo lado mau destas. Por isso se vêem atualmente tantos crimes, nos quais percebemos uma gratuita estranheza que "só se explica por nossa impotência para possuir a vida." ${ }^{26}$ Artaud rejeita a sua atualidade e reivindica uma outra, capaz de tirar a humanidade da beira do abismo onde ela se encontra. Virmaux, a esse respeito, nos diz em seu livro Artaud e o Teatro: "vivemos todos atualmente em um contínuo mal-estar e, portanto, precisamos de um teatro que nos auxilie a superar nossa angústia, como as festas teatrais da Antigüidade ajudavam os homens a exorcizar seu medo dos deuses."27

Em um outro momento do diálogo é dito:

La terre et le ciel on s'en balance!

La Science, on n'y comprend rien!

Começa a ser preparado aqui o "Movimento IV", cuja discussão girará em torno da explicação científica para toda a "bagunça" cósmica. Após a presença do coro, a cena fica novamente calma e entra uma noite vocal, luminosa e instrumental. Vimos que toda a mudança brusca de ritmo da peça acontece na passagem de um movimento para outro, é o que ocorre aqui. Esse último movimento (a peça é interrompida no ato IV, uma vez que Artaud não a finalizou) começa, como os outros, de maneira tranqüila, agitando-se no seu decorrer.

A luz dá início à cena mostrando um cientista no alto de uma gigantesca ponte de ferro. Posteriormente, os seus estranhos aparelhos são colocados em evidência de maneira a serem vistas algumas explosões. Outros grupos de cientistas entram e preenchem a cena com as suas discussões. Interessante é a forma como são descritos:

(...) tous les savantas ont des têtes faites correspondant à tous les degrés de la bêtise et de la médiocrité officielles. Ils sont caricaturaux mais sans excés.

Claro está, através deste período, a maneira como Artaud vê os cientistas de sua época. As personagens que os representam, apesar de serem "caricaturas sem excesso" mostram, ao longo de uma conversação travada nesse movimento, como tais cientistas não passam de pretensiosos e dissimuladores da realidade. Alguns trabalham em proveito não do bem estar geral, mas de múltiplas utilizações industriais. Outros discordam de tais posições e podemos ver em suas palavras o eco de um grito que certamente é de Artaud:

Mais ce n'est plus de la science, c'est immoral.

O mundo moderno é regido por uma ciência męcanizada. Nele, falar em leis superiores corresponde a elevar a risada já que a vida não passa de um museu. Tal é para Artaud o quadro da vida moderna orientada pela ciência: o sentido mágico das coisas se 
dissolveu e todos se perdem em explicações que não significam nada. Nessa época, que tem como signo a confusão, não faltam sistemas de pensamento que a querem explicar, mas é preciso pensar quando a nossa vida foi realmente afetada por eles. No texto intitulado "O homem contra o destino", Artaud deixa claro como concebe os meios experimentais científicos: "Nós rejeitamos os ensinamentos da experiência e nós não acreditamos no valor da experiência e na prova pela experiência. Todas as formas de experiência dissimulam a realidade." ${ }^{28}$ Para ele, a racionalização demasiada da existência nos impede de nos pensar e de agirmos de acordo com a nossa imaginação e criação.

Por meio de uma mudança na maneira de fazer o teatro poderemos devolver a magia à vida e, assim, mudar esse estado caótico no qual o espírito se alojou. Para tanto, "a questão que agora se coloca é saber se neste mundo em declínio, que está se suicidando sem perceber, haverá um núcleo de homens capazes de impor essa noção superior do teatro, que devolverá a todos nós o equivalente natural e mágico dos dogmas em que não acreditamos mais."29

\section{BIBLIOGRAFIA}

ARTAUD, Antonin. Oeuvres Complétes, Gallimard Tomos: II, IV e VIII, 1970-1974.

O teatro e seu Duplo. São Paulo: Martins Fontes, 1993.

Linguagem e Vida. São Paulo: Perspectiva, 1995.

$A$ arte e a morte. Lisboa: Mm Livreiros Editores, 1987

VIRMAUX, Alain. Artaud e o Teatro. São Paulo: Perspectiva, 1978.

FELÍCIO, V. L. G., A Procura da Lucidez em Artaud. Tese de doutoramento, Depto. de Filosofia, F.F.L.C.H., USP, 1980.

"Espaço da cultura no pensamento de Artaud". São Paulo, 1985 (in

Discurso, São Paulo, p. 147,51)

FREITAS, L. F. V., A Crueldade de Artaud. Dissertação de mestrado, Depto de Filosofia, F.F.L.C.H., USP, 1980.

ARANTES, Urias Correa, Artaud: Teatro e Cultura. Dissertação de mestrado, Depto. De Filosofia, F.F.L.C.H., USP, 1980.

\section{NOTAS}

1. Artaud, "O Umbigo dos Limbos" in Linguagem e Vida, p. 207.

2. Artaud, Oeuvres Complètes (Tome II) todas as citações da peça referem-se a essa edição. Citaremos no original francês por não termos encontrado uma versão traduzida e nos considerarmos inaptos a essa tarefa.

3. Artaud, O Teatro e seu Duplo, p. 117

4. Id., ibid, p. 83.

5. Id., ibid, p. 85.

6. Felício, Vera Lúcia, "Espaço da cultura no pensamento de Artaud" in Discurso, São Paulo, n.15, p.149.

7. Virmaux, Alain. Artaud e o Teatro, p. 43.

8. Artaud, O Teatro e seu Duplo, p. 85. 
9. Id., ibid, p. 118.

10. Id., ibid, p.83.

11. Id., ibid, p. 83.

12. Felício, Vera Lúcia. A procura da lucidez em Artaud, p. 145.

13. A guerra também está relacionada a essa idéia de epidemia, tal qual a descrevemos em Artaud.

14. Artaud, O Teatro e seu Duplo, p.24.

15. Id., ibid, p.26.

16. Id., ibid, p.02.

17 Virmaux, Artaud e o Teatro, p.58.

18. Artaud, O Teatro e seu Duplo, p.61.

19. Um exemplo que Virmaux cita é o encontrado em J. P. Sartre, na obra La Grande Peur (1948), roteiro de cinema inédito.

20. Artaud, O Teatro e seu Duplo, p.91.

21. Id., ibid, p.114.

22. Id., ibid, p. 115 .

23. Id., ibid, p.76.

24. Id., ibid, p.77.

25. Artaud, Ouvres Complètes, Tome VIII, p.207

26. Artaud, O Teatro e seu Duplo, p. 03.

27. Virmaux, Artaud e o Teatro, p.58.

28. Id., ibid, p.156.

29. Artaud, O Teatro e seu Duplo, p. 26. 